\title{
BM]
}

\section{Risk of cardiovascular events among women with high normal blood pressure or blood pressure progression: prospective cohort study}

\author{
David Conen, research fellow, ${ }^{1}$ Paul M Ridker, professor of medicine, ${ }^{2}$ Julie E Buring, professor of medicine, ${ }^{1}$ \\ Robert J Glynn, associate professor of medicine (biostatistics) ${ }^{1}$
}

\begin{abstract}
${ }^{1}$ Division of Preventive Medicine Department of Medicine, Brigham and Women's Hospital, Harvard Medical School, 900 Commonwealth Avenue, Boston, MA 02215, USA

${ }^{2}$ Divisions of Preventive Medicine and Cardiovascular Medicine,

Department of Medicine, Brigham and Women's Hospital Correspondence to: D Conen conend@uhbs.ch
\end{abstract}

doi:10.1136/bmj.39269.672188.AE

\section{ABSTRACT}

Objective To compare cardiovascular risk among women with high normal blood pressure (130-9/85-9 mm $\mathrm{Hg}$ ) against those with normal blood pressure (120-9/ 75-84 $\mathrm{mm} \mathrm{Hg}$ ) and those with baseline hypertension.

Design Prospective cohort study.

Setting Women's health study, United States.

Participants 39322 initially healthy women classified into four categories according to self reported baseline blood pressure and followed for a median of 10.2 years.

Main outcome measures Time to cardiovascular death, myocardial infarction, or stroke (major cardiovascular event-primary end point); progression to hypertension.

Results 982 (2.5\%) women developed a major cardiovascular event, and 8686 (30.1\%) women without baseline hypertension progressed to hypertension. The age adjusted event rate for the primary end point was $1.6 / 1000$ person years among women with normal blood pressure, 2.9/1000 person years among those with high normal blood pressure, and 4.3/1000 person years among those with baseline hypertension. Compared with women with high normal blood pressure (reference group), those with normal blood pressure had a lower risk of a major cardiovascular event (adjusted hazard ratio $0.61,95 \%$ confidence interval 0.48 to 0.76 ) and of incident hypertension $(0.42,0.40$ to 0.44$)$. The hazard ratio for a major cardiovascular event in women with baseline hypertension was 1.30 (1.08 to 1.57). Women who progressed to hypertension (reference group) during the first 48 months of the study had a higher cardiovascular risk than those who remained normotensive (adjusted hazard ratio $0.64,0.50$ to 0.81 ). Women with high normal blood pressure at baseline who progressed to hypertension (reference group) had similar outcome rates to women with baseline hypertension (adjusted hazard ratio $1.17,0.88$ to 1.55 ).

Conclusion The cardiovascular risk of women with high normal blood pressure is higher than that of women with normal blood pressure. The cardiovascular risk of women who progress to hypertension is increased shortly after a diagnosis of hypertension has been made.

Trial registration Clinical trials NCT00000479.

\section{INTRODUCTION}

Hypertension is defined as a systolic blood pressure of at least $140 \mathrm{~mm} \mathrm{Hg}$ or a diastolic blood pressure of at least $90 \mathrm{~mm} \mathrm{Hg}$. However, cardiovascular risk is directly associated with blood pressure across a much wider spectrum of blood pressure levels, and no evidence of a threshold exists down to at least 115/ $75 \mathrm{~mm} \mathrm{Hg} .{ }^{12}$ Although this relation is firmly established, little evidence is available about the risk of cardiovascular events in people whose blood pressure levels progress and who newly develop hypertension.

This question is important because people with blood pressure levels in the normal and high normal range have a substantial risk of developing hypertension over a short term period of four years. ${ }^{3}$ The cumulative lifetime risk of developing hypertension approaches $90 \%$ in a Western population, ${ }^{4}$ and the high global prevalence of hypertension further underscores the importance of the problem. ${ }^{5}$

Strategies to prevent or postpone hypertension in people with normal blood pressure could thus have a substantial impact on public health. Unfortunately, published guidelines for the management of people with hypertension have adopted different classification schemes for patients with blood pressure levels considered to be normal. ${ }^{67}$ The Joint National Committee 7 guidelines from the United States introduced a category designated "prehypertension" for people with blood pressure levels from 120 to $139 \mathrm{~mm} \mathrm{Hg}$ for systolic pressure or 80 to $89 \mathrm{~mm} \mathrm{Hg}$ for diastolic pressure. ${ }^{7}$ On the other hand, the European guidelines partition these people into two groups: those with systolic blood pressure between 120 and $129 \mathrm{~mm} \mathrm{Hg}$ or diastolic blood pressure between 80 and $84 \mathrm{~mm} \mathrm{Hg}$ are classified as normal, whereas those with systolic blood pressure between 130 and $139 \mathrm{~mm} \mathrm{Hg}$ or diastolic blood pressure between 85 and $89 \mathrm{~mm} \mathrm{Hg}$ are classified as high normal. ${ }^{6}$ Evidence for a different clinical course among people in these two groups would support the relevance of this distinction. We therefore determined the long term outcome with regard to cardiovascular disease and progression to hypertension in a large cohort of initially healthy women with a wide range of blood pressures. We then evaluated in greater detail 
the outcome of women who developed hypertension during the first 48 months of the study.

\section{METHODS}

Participants

All the women studied were participants in the women's health study, a completed randomised trial that evaluated the risks and benefits of low dose aspirin and vitamin $\mathrm{E}$ in the primary prevention of cardiovascular disease and cancer. Details of the study design have been described previously. ${ }^{8-10}$

Briefly, beginning in 1993, 39876 female health professionals in the United States who were 45 years or older and free of cardiovascular disease, cancer, or other major illnesses were randomised to receive $100 \mathrm{mg}$ aspirin every other day, $600 \mathrm{IU}$ vitamin $\mathrm{E}$ every other day, both agents, or placebo. The trial initially had a $\beta$ carotene arm, which was terminated early. ${ }^{11}$ Information on baseline variables was collected with mailed questionnaires. Follow-up questionnaires asking participants about study outcomes and other information were sent every six months during the first year and every 12 months thereafter.

We used follow-up information from randomisation to the end of the trial on 31 March 2004 for this analysis. As of this date, follow-up was $97.2 \%$ complete for morbidity and $99.4 \%$ complete for mortality. For this analysis, the study population consisted of all 39322 women with complete information about blood pressure, personal history of hypertension, and antihypertensive treatment at randomisation. We analysed incident hypertension among 28863 $(73.4 \%)$ women without hypertension at baseline. The median follow-up in this study was 10.2 years. Written informed consent was obtained from all participants, and the trial was monitored by an external data and safety monitoring board.

\section{Study variables}

Blood pressure at randomisation was self reported by the female health professionals, a group in which self report of blood pressure has proved highly accurate..$^{1-12}$ Participating women categorised their blood pressure levels into nine different categories for systolic blood pressure and seven different categories for diastolic blood pressure. The Spearman correlation coefficient of categories of blood pressure at baseline and at 12 months was 0.75 for systolic blood pressure and 0.64 for diastolic blood pressure. These coefficients compare favourably with those found for measured blood pressure. ${ }^{13-15}$

For the purpose of this study, we classified women into four predefined blood pressure categories: below $120 \mathrm{~mm} \mathrm{Hg}$ for systolic pressure and $75 \mathrm{~mm} \mathrm{Hg}$ for diastolic pressure (subsequently called optimal blood pressure), $120-9 \mathrm{~mm} \mathrm{Hg}$ for systolic pressure or 75-84 $\mathrm{mm} \mathrm{Hg}$ for diastolic pressure (subsequently called normal blood pressure), $130-9 \mathrm{~mm} \mathrm{Hg}$ for systolic pressure or 85-9 $\mathrm{mm} \mathrm{Hg}$ for diastolic pressure (subsequently called high normal blood pressure), and established hypertension. We defined established hypertension as self reported history of hypertension, taking antihypertensive treatment, or blood pressure levels of at least $140 \mathrm{~mm} \mathrm{Hg}$ for systolic pressure or $90 \mathrm{~mm} \mathrm{Hg}$ for diastolic pressure. We classified women with discordant systolic and diastolic blood pressure categories into the higher category.

Covariates of interest were self reported at study entry and included age, smoking, history of hypercholesterolaemia (self reported cholesterol of at least $240 \mathrm{mg} / \mathrm{dl}(6.22 \mathrm{mmol} / \mathrm{l}))$, diabetes, body mass index (weight in kilograms divided by the square of height in metres), exercise, alcohol consumption, and highest educational level achieved.

\section{Ascertainment of cardiovascular outcome variables}

We asked all women who reported a myocardial infarction, stroke, or coronary revascularisation (percutaneous coronary angioplasty or bypass surgery) for permission to review their medical records. We confirmed that death was from cardiovascular causes on the basis of autopsy records, death certificates, medical records, or information obtained from family members. An endpoint committee of physicians reviewed medical records for reported events according to predefined criteria. We included only confirmed events in this analysis.

\section{Definition of incident hypertension}

We defined incident cases of hypertension for women without hypertension at baseline as meeting at least one of the following criteria: self report of a new diagnosis by a physician of hypertension at years 1 and 3 and yearly thereafter; self report of taking antihypertensive treatment at years 1, 3, and 4 and at the end of the study; or self reported blood pressure of at least $140 \mathrm{~mm} \mathrm{Hg}$ for systolic pressure or $90 \mathrm{~mm} \mathrm{Hg}$ for diastolic pressure at years 1 and 4 and at the end of the study.

Women who reported a new diagnosis of hypertension by a physician also provided the month and year of diagnosis. For a diagnosis defined by another criterion or a missing date for a physician's diagnosis, we randomly assigned a date between the latest questionnaire and the previous one. Women who developed cardiovascular disease, for which the management may interfere with blood pressure levels, were censored at the date of diagnosis and not considered at risk for incident hypertension thereafter.

\section{Statistical analysis}

The primary cardiovascular outcome variable was a composite of myocardial infarction, stroke, and death from cardiovascular causes. We also analysed the individual components, coronary revascularisation, and death from any cause as secondary variables. If a woman had several events, we counted only the first event in each category.

Blood pressure category and cardiovascular events We calculated age adjusted incidences per 1000 person years stratified by blood pressure category for the 
primary and all secondary outcome variables. Subsequently, we constructed Cox proportional hazards models to calculate hazard ratios and 95\% confidence intervals for the comparison of event rates in the four blood pressure categories. We chose the high normal blood pressure category as the reference group, because it constituted the main focus of this study. In a first step, we adjusted the crude models for age. Thereafter, we fitted a multivariable model adjusting for age, smoking, history of diabetes, body mass index, history of hypercholesterolaemia, exercise, alcohol consumption, highest educational level, and randomised treatment assignments (aspirin, vitamin $\mathrm{E}$, and $\beta$ carotene).

Blood pressure category and progression to hypertension We calculated age adjusted incidences per 1000 person years for the development of incident hypertension during follow-up among women without hypertension at baseline, again stratified by blood pressure category. To compare the event rates among the different blood pressure categories, we constructed Cox proportional hazards models to calculate the adjusted blood pressure category specific hazard ratios for incident hypertension. Again, women with high normal blood pressure constituted the reference group. We adjusted this model for the same variables described above.

\section{Blood pressure progression and cardiovascular events}

We then categorised women into the following prespecified categories: women without baseline hypertension who did not develop hypertension during the first 48 months of follow-up, women with baseline hypertension, and women without baseline hypertension who developed hypertension during the first 48 months of follow-up. In a second step, we further

Table 1| Baseline characteristics according to blood pressure category. Values are numbers (percentages) unless stated otherwise

\begin{tabular}{|c|c|c|c|c|}
\hline \multirow[b]{2}{*}{ Characteristics } & \multicolumn{4}{|c|}{ Baseline blood pressure, systolic/diastolic $(\mathrm{mm} \mathrm{Hg})$} \\
\hline & $\begin{array}{c}\langle 120 / 75 \\
(n=12549)^{\star}\end{array}$ & $\begin{array}{c}120-9 / 75-84 \\
(n=11326)^{*}\end{array}$ & $\begin{array}{c}130-9 / 85-9 \\
(\mathrm{n}=4988)^{*}\end{array}$ & $\begin{array}{c}\text { Hypertension† } \\
(\mathrm{n}=10459)^{\star}\end{array}$ \\
\hline Mean (SD) age (years) & $53(6)$ & $54(7)$ & $56(7)$ & $57(8)$ \\
\hline Mean (SD) body mass index $\left(\mathrm{kg} / \mathrm{m}^{2}\right)$ & $24.0(3.7)$ & $25.6(4.4)$ & $27.3(5.3)$ & $28.4(5.9)$ \\
\hline \multicolumn{5}{|l|}{ History of diabetes: } \\
\hline Yes & $82(0.7)$ & $153(1.4)$ & $143(2.9)$ & $639(6.1)$ \\
\hline No & $12463(99.4)$ & $11164(98.7)$ & $4842(97.1)$ & $9812(93.9)$ \\
\hline \multicolumn{5}{|l|}{ History of hypercholesterolaemia: } \\
\hline Yes & 2708 (21.6) & $2893(25.6)$ & $1551(31.1)$ & $4486(42.9)$ \\
\hline No & $9837(78.4)$ & $8430(74.5)$ & $3432(68.9)$ & $5969(57.1)$ \\
\hline \multicolumn{5}{|l|}{ Smoking: } \\
\hline Current & $1726(13.8)$ & $1469(13.0)$ & $681(13.7)$ & $1277(12.2)$ \\
\hline Former & $4517(36.0)$ & $4003(35.4)$ & $1786(35.9)$ & $3759(36.0)$ \\
\hline Never & $6296(50.2)$ & $5849(51.7)$ & $2514(50.5)$ & $5411(51.8)$ \\
\hline \multicolumn{5}{|l|}{ Hormone replacement therapy: } \\
\hline Never & $6466(51.6)$ & $5744(50.8)$ & $2505(50.3)$ & $4836(46.3)$ \\
\hline Former & $895(7.2)$ & $925(8.2)$ & $501(10.1)$ & $1241(11.9)$ \\
\hline Current & $5160(41.2)$ & $4641(41.0)$ & $1973(39.6)$ & $4359(41.8)$ \\
\hline \multicolumn{5}{|l|}{ Exercise (times/week): } \\
\hline Rarely/never & $4102(32.7)$ & $4233(37.4)$ & $2053(41.2)$ & $4683(44.8)$ \\
\hline$\ll 1$ & 2494 (19.9) & $2317(20.5)$ & $1017(20.4)$ & $1986(19.0)$ \\
\hline $1-3$ & $4253(33.9)$ & 3615 (31.9) & $1519(30.5)$ & $2861(27.4)$ \\
\hline 13 & $1692(13.5)$ & 1159 (10.2) & 395 (7.9) & $925(8.9)$ \\
\hline \multicolumn{5}{|l|}{ Alcohol consumptionł: } \\
\hline Rarely/never & $5240(41.8)$ & $4893(43.2)$ & $2281(45.7)$ & $5339(51.1)$ \\
\hline 1-3 drinks/month & 1744 (13.9) & $1470(13.0)$ & $634(12.7)$ & $1327(12.7)$ \\
\hline 1-6 drinks/week & 4327 (34.5) & $3784(33.4)$ & $1527(30.6)$ & $2751(26.3)$ \\
\hline$\geq 1 \mathrm{drink} /$ day & $1235(9.8)$ & $1175(10.4)$ & $545(10.9)$ & $1040(10.0)$ \\
\hline White race & $11912(95.7)$ & $10729(95.6)$ & $4706(95.2)$ & $9612(92.7)$ \\
\hline \multicolumn{5}{|l|}{ Highest educational level: } \\
\hline Less than a bachelors degree & $6583(53.3)$ & $6127(55.0)$ & $2962(60.3)$ & $6543(63.7)$ \\
\hline Bachelors degree & $3132(25.4)$ & $2642(23.7)$ & 1075 (21.9) & $2069(20.2)$ \\
\hline Masters degree or doctorate & $2641(21.4)$ & $2372(21.3)$ & $872(17.8)$ & $1657(16.1)$ \\
\hline
\end{tabular}

*Number of women across categories may not sum to the given number because of missing data.

†Defined as previous diagnosis of hypertension, systolic blood pressure $\geq 140 \mathrm{~mm} \mathrm{Hg}$, diastolic blood pressure $\geq 90 \mathrm{~mm} \mathrm{Hg}$, or receiving blood pressure lowering treatment.

‡One drink corresponds to $13 \mathrm{~g}$ alcohol. 
subdivided the last group into one group with baseline blood pressure values below 130/85 $\mathrm{mm} \mathrm{Hg}$ and another group with baseline blood pressure values between 130 and $139 \mathrm{~mm} \mathrm{Hg}$ for systolic pressure or between 85 and $89 \mathrm{~mm} \mathrm{Hg}$ for diastolic pressure.

We constructed Cox proportional hazards models to compare the hazard ratios for developing a primary cardiovascular outcome event between these newly created categories. Because we assessed time to a first cardiovascular event beginning at month 48 , women who had a primary cardiovascular outcome event or died during the first 48 months of follow-up were excluded from these analyses. We adjusted this model for age, smoking, diabetes, body mass index, and alcohol consumption at 48 months and for baseline history of hypercholesterolaemia, exercise, highest educational level, and randomised treatment assignments.

We entered categorical variables in the Cox models by using binary indicator variables. We used integer scores across categories to test for trend. We examined the proportional hazards assumption for all models by including a blood pressure category by time interaction in the model. ${ }^{16}$ We used SAS version 9 for all analyses. A two tailed $\mathrm{P}$ value $<0.05$ indicated statistical significance.

\section{RESULTS}

Table 1 shows baseline characteristics stratified by blood pressure category. At baseline, 10459 (26.6\%) of the study participants had hypertension, 4988 $(12.7 \%)$ had high normal blood pressure, 11326 $(28.8 \%)$ had normal blood pressure, and 12549 $(31.9 \%)$ had optimal blood pressure. Increasing blood

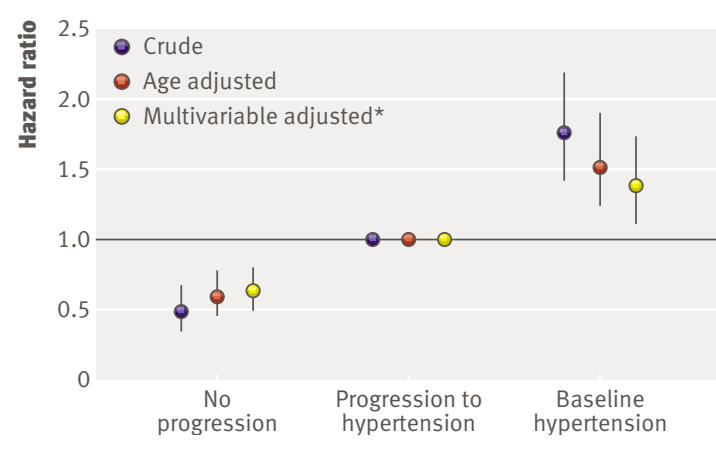

Fig 1 Blood pressure progression and risk of major cardiovascular events. Hazard ratios (with 95\% confidence intervals) for a first major cardiovascular event in women with incident hypertension during the first $\mathbf{4 8}$ months (reference group), compared with women with persistent normotension and women with hypertension at baseline. The different categories are defined in table 5. *Adjusted for age, smoking, diabetes, body mass index, and alcohol consumption at 48 months and for baseline history of hypercholesterolaemia, exercise, highest educational level, and randomised treatment assignments

pressure was associated with increasing age and body mass index and a higher prevalence of diabetes and hypercholesterolaemia. Moderate alcohol consumption, exercise, higher educational level, and white race were more prevalent in women with lower blood pressure levels.

Blood pressure category and cardiovascular events After 10.2 years of follow-up, 982 confirmed major cardiovascular events had occurred among 39322 women. Table 2 shows age adjusted event rates

\begin{tabular}{|c|c|c|c|c|}
\hline \multirow[b]{2}{*}{ Endpoint } & \multicolumn{4}{|c|}{ Baseline blood pressure, systolic/diastolic $(\mathrm{mm} \mathrm{Hg})$} \\
\hline & $<120 / 75$ & $120-9 / 75-84$ & $130-9 / 85-9$ & Hypertension* \\
\hline \multicolumn{5}{|l|}{ Major cardiovascular event $\dagger$} \\
\hline No of events/person years & $134 / 125503$ & $176 / 112972$ & $159 / 49214$ & $513 / 102040$ \\
\hline Age adjusted incidence & 1.28 & 1.64 & 2.92 & 4.32 \\
\hline \multicolumn{5}{|l|}{ Stroke } \\
\hline No of events/person years & $79 / 125659$ & $85 / 113247$ & $63 / 49531$ & $251 / 102857$ \\
\hline Age adjusted incidence & 0.74 & 0.79 & 1.15 & 2.09 \\
\hline \multicolumn{5}{|l|}{ Myocardial infarction } \\
\hline No of events/person years & $42 / 125790$ & $70 / 113286$ & $77 / 49464$ & $200 / 102976$ \\
\hline Age adjusted incidence & 0.41 & 0.65 & 1.42 & 1.73 \\
\hline \multicolumn{5}{|c|}{ Death from cardiovascular causes } \\
\hline No of events/person years & $30 / 125952$ & $37 / 113562$ & $32 / 49781$ & $140 / 103835$ \\
\hline Age adjusted incidence & 0.29 & 0.34 & 0.55 & 1.09 \\
\hline \multicolumn{5}{|l|}{ Coronary revascularisation } \\
\hline No of events/person years & $93 / 125648$ & $123 / 113080$ & $140 / 49204$ & $392 / 102167$ \\
\hline Age adjusted incidence & 0.91 & 1.12 & 2.61 & 3.49 \\
\hline \multicolumn{5}{|l|}{ Death from any cause } \\
\hline No of events/person years & $224 / 125952$ & $243 / 113562$ & $153 / 49781$ & $457 / 103835$ \\
\hline Age adjusted incidence & 2.11 & 2.27 & 2.80 & 3.65 \\
\hline
\end{tabular}

*Defined as previous diagnosis of hypertension, systolic blood pressure $\geq 140 \mathrm{~mm} \mathrm{Hg}$, diastolic blood pressure $\geq 90 \mathrm{~mm} \mathrm{Hg}$, or receiving blood pressure lowering treatment.

tDefined as myocardial infarction, stroke, or death from cardiovascular causes. 
stratified by blood pressure category. Women with hypertension at baseline had the highest event rate (4.32 major cardiovascular events per 1000 person years). We saw a strong and consistent decrease in event rates down to the optimal blood pressure category among all primary and secondary outcomes evaluated. Of particular interest, the rate of major cardiovascular events among women with high normal blood pressure at baseline was almost twice as high as that for those with normal baseline blood pressure.

Multivariable Cox proportional hazards models only slightly attenuated the strong trend across blood pressure categories (table 3). In the fully adjusted model, women with normal blood pressure at baseline had a $39 \%$ lower risk of having a major cardiovascular event compared with those with high normal blood pressure and those with optimal blood pressure at baseline had a $49 \%$ lower risk. The risk of women with established hypertension at baseline was $30 \%$ higher.

Women with hypertension had a substantially higher risk of stroke than women with high normal blood pressure (hazard ratio 1.61, 95\% confidence interval 1.21 to 2.14 ), but the risk of coronary events (myocardial infarction or coronary revascularisation) did not differ significantly between the two groups. The lower risk of cardiovascular events in women with normal blood pressure compared with those with high normal blood pressure was consistent among all individual end points considered, although some of the secondary end points did not reach statistical significance in the fully adjusted models.

Blood pressure category and progression to hypertension In total, $8686(30.1 \%)$ of the 28863 women without a diagnosis of hypertension at baseline developed incident hypertension during follow-up. The incidence of hypertension strongly increased across the different blood pressure categories, ranging from 16.0 events per 1000 person years in women with optimal blood pressure to 114.7 per 1000 person years in women with high normal blood pressure at baseline (table 4). Across the three baseline blood pressure categories, $8.2 \%, 22.7 \%$, and $51.8 \%$ of women developed hypertension after five years of follow-up. The corresponding 10 year cumulative risks of incident hypertension were 14.8\%, 34.0\%, and $64.2 \%$. Women with normal blood pressure thus had a substantially lower risk of developing hypertension than women with high normal blood pressure.

Table 3 | Cox proportional hazards models to compare risk of first cardiovascular event according to baseline blood pressure category. Values are hazard ratios ( $95 \%$ confidence intervals)

\begin{tabular}{|c|c|c|c|c|}
\hline \multirow[b]{2}{*}{ Endpoint } & \multicolumn{4}{|c|}{ Baseline blood pressure, systolic/diastolic (mm Hg) } \\
\hline & $<120 / 75$ & $120-9 / 75-84$ & $130-9 / 85-9 *$ & Hypertension $†$ \\
\hline \multicolumn{5}{|c|}{ Major cardiovascular event $\ddagger$} \\
\hline Crude & 0.33 (0.26 to 0.42$)$ & $0.48(0.39$ to 0.60$)$ & 1.0 & $1.56(1.30$ to 1.86$)$ \\
\hline Age adjusted & $0.44(0.35$ to 0.55$)$ & $0.56(0.45$ to 0.70$)$ & 1.0 & $1.41(1.18$ to 1.69$)$ \\
\hline Multivariable adjusted§ & $0.51(0.40$ to 0.64$)$ & $0.61(0.48$ to 0.76$)$ & 1.0 & $1.30(1.08$ to 1.57$)$ \\
\hline \multicolumn{5}{|l|}{ Stroke } \\
\hline Crude & $0.49(0.36$ to 0.69$)$ & $0.59(0.43$ to 0.82$)$ & 1.0 & $1.92(1.46$ to 2.53$)$ \\
\hline Age adjusted & $0.66(0.47$ to 0.92$)$ & 0.69 (0.50 to 0.96$)$ & 1.0 & 1.74 (1.32 to 2.29$)$ \\
\hline Multivariable adjusted§ & $0.72(0.51$ to 1.01$)$ & $0.74(0.53$ to 1.03$)$ & 1.0 & $1.61(1.21$ to 2.14$)$ \\
\hline \multicolumn{5}{|l|}{ Myocardial infarction } \\
\hline Crude & 0.21 (0.15 to 0.31$)$ & $0.40(0.29$ to 0.55$)$ & 1.0 & $1.25(0.96$ to 1.62$)$ \\
\hline Age adjusted & 0.27 (0.19 to 0.40$)$ & $0.45(0.33$ to 0.63$)$ & 1.0 & 1.15 (0.88 to 1.50$)$ \\
\hline Multivariable adjusted§ & $0.34(0.23$ to 0.50$)$ & $0.50(0.36$ to 0.71$)$ & 1.0 & $1.03(0.78$ to 1.35$)$ \\
\hline \multicolumn{5}{|c|}{ Death from cardiovascular causes } \\
\hline Crude & $0.37(0.23$ to 0.61$)$ & $0.51(0.32$ to 0.81$)$ & 1.0 & 2.10 (1.43 to 3.08$)$ \\
\hline Age adjusted & $0.55(0.33$ to 0.91$)$ & $0.63(0.39$ to 1.01$)$ & 1.0 & $1.83(1.25$ to 2.69$)$ \\
\hline Multivariable adjusted§ & $0.66(0.39$ to 1.10$)$ & $0.65(0.39$ to 1.06$)$ & 1.0 & $1.68(1.13$ to 2.50$)$ \\
\hline \multicolumn{5}{|l|}{ Coronary revascularisation } \\
\hline Crude & $0.26(0.20$ to 0.34$)$ & 0.38 (0.30 to 0.49$)$ & 1.0 & $1.35(1.12$ to 1.64$)$ \\
\hline Age adjusted & $0.31(0.24$ to 0.41$)$ & $0.42(0.33$ to 0.54$)$ & 1.0 & $1.26(1.04$ to 1.53$)$ \\
\hline Multivariable adjusted§ & 0.38 (0.29 to 0.50$)$ & $0.49(0.38$ to 0.64$)$ & 1.0 & $1.08(0.88$ to 1.32$)$ \\
\hline \multicolumn{5}{|l|}{ Death from any cause } \\
\hline Crude & $0.58(0.47$ to 0.71$)$ & $0.70(0.57$ to 0.85$)$ & 1.0 & $1.43(1.19$ to 1.72$)$ \\
\hline Age adjusted & 0.81 (0.66 to 1.00$)$ & 0.84 (0.69 to 1.03$)$ & 1.0 & 1.27 (1.06 to 1.53$)$ \\
\hline Multivariable adjusted§ & 0.91 (0.73 to 1.13$)$ & $0.89(0.72$ to 1.10$)$ & 1.0 & $1.26(1.04$ to 1.52$)$ \\
\hline
\end{tabular}

*Reference category.

†Defined as previous diagnosis of hypertension, systolic blood pressure $\geq 140 \mathrm{~mm} \mathrm{Hg}$, diastolic blood pressure $\geq 90 \mathrm{~mm} \mathrm{Hg}$, or receiving blood pressure lowering treatment.

tDefined as myocardial infarction, stroke, or death from cardiovascular causes.

§Adjusted for age, smoking, diabetes, history of hypercholesterolaemia, body mass index, exercise, alcohol consumption, highest educational level, and randomised treatment assignments (aspirin, vitamin $\mathrm{E}$, and $\beta$ carotene); owing to missing covariates, the multivariable (crude) analysis was based on 930 (982) major cardiovascular events, 456 (478) strokes, 365 (389) myocardial infarctions, 226 (239) cardiovascular deaths, 706 (748) revascularisations, and 1025 (1077) all cause deaths among 37787 (39 322) women. 
This large difference persisted over the entire follow-up period and remained almost unchanged after multivariable adjustment (hazard ratio $0.42,0.40$ to 0.44 ) (table 4 ). We found evidence of violation of the proportional hazards assumption, with a greater relative hazard during early follow-up and attenuation over time.

\section{Blood pressure progression and cardiovascular events}

During the first 48 months of follow-up, 22886 (59.0\%) women remained free of hypertension, $5694(14.7 \%)$ progressed to hypertension (3274 (57.5\%) women with baseline blood pressure below 130/85 mm Hg and $2420(42.5 \%)$ women with high normal blood pressure at baseline), and 10207 (26.3\%) already had hypertension at baseline. We excluded 535 (1.4\%) women with a major cardiovascular event or death during the first 48 months from these analyses.

Women who progressed to hypertension had a higher event rate during follow-up than women who remained free of hypertension and a lower event rate than women with hypertension at baseline (table 5). This difference between women with incident hypertension and baseline hypertension was substantially attenuated after multivariable adjustment, but having hypertension at baseline remained associated with a significant 39\% increase in risk (table 5, fig 1). After multivariable adjustment, women without progression to hypertension during the first 48 months had a $36 \%$ lower risk than women who progressed to hypertension.

In the second model, we found that women who had high normal blood pressure at baseline and who progressed to hypertension during follow-up had a similar risk of a major cardiovascular event to women with hypertension at baseline $(\mathrm{P}=0.28)$. Women who had a lower blood pressure at baseline and who progressed to hypertension had a 30\% lower risk of a cardiovascular event than women with high normal blood pressure at baseline, a difference that was of borderline statistical significance $(\mathrm{P}=0.07)$ (table 5, fig 2).

\section{DISCUSSION}

This study provides evidence that women's risk of having a major cardiovascular event is lower at lower blood pressure, without evidence of a threshold level. Our findings are in line with previous reports from two

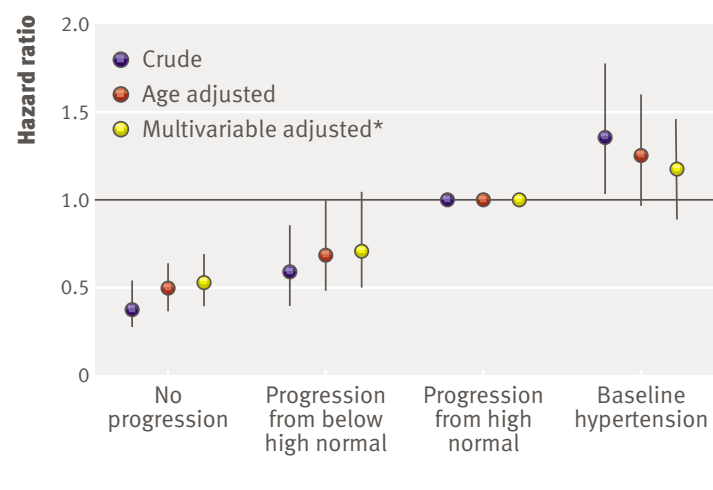

Fig 2 | Blood pressure progression and risk of major cardiovascular events stratified by baseline blood pressure. Hazard ratios (with $95 \%$ confidence intervals) for a first major cardiovascular event in women with high normal blood pressure at baseline and incident hypertension in the first 48 months (reference group), compared with women with persistent normotension, women with below high normal baseline blood pressure and incident hypertension in the first 48 months, and women with hypertension at baseline. The different categories are defined in table 5. *Adjusted for age, smoking, diabetes, body mass index, and alcohol consumption at 48 months and for baseline history of hypercholesterolaemia, exercise, highest educational level, and randomised treatment assignments

different cohort studies and from a large metaanalysis. ${ }^{1217}$ In contrast to the previous studies, we focused our attention on women with high normal blood pressure and found that their risk of having a major cardiovascular event was $64 \%$ higher compared with women with normal blood pressure and almost doubled compared with women with optimal blood pressure at baseline.

These differences are important for several reasons. By combining the two categories normal and high normal blood pressure, the Joint National Committee 7 guidelines created a new blood pressure category called "prehypertension."" However, because of the large differences in cardiovascular risk, separate consideration of these two groups may be reasonable. By maintaining two different blood pressure categories (normal and high normal blood pressure), the European guidelines for the management of

Table 4 | Risk of developing hypertension among 28863 women without hypertension at baseline

\begin{tabular}{|c|c|c|c|c|}
\hline & \multicolumn{3}{|c|}{ Baseline blood pressure level, systolic/diastolic (mm Hg) } & \multirow[b]{2}{*}{ P for trend } \\
\hline & $<120 / 75$ & $120-9 / 75-84$ & $130-9 / 85-9$ & \\
\hline \multicolumn{5}{|l|}{ Absolute risk of developing hypertension } \\
\hline No of events/person years & $1796 / 115700$ & $3765 / 89999$ & $3125 / 26764$ & \\
\hline Age adjusted incidence/1000 person years & 16.0 & 41.8 & 114.7 & \\
\hline \multicolumn{5}{|l|}{ Hazard ratio ( $95 \%$ confidence interval) } \\
\hline Crude & 0.14 (0.13 to 0.15$)$ & $0.38(0.36$ to 0.40$)$ & $1.0^{*}$ & $<0.0001$ \\
\hline Age adjusted & $0.15(0.14$ to 0.16$)$ & $0.39(0.37$ to 0.41$)$ & $1.0^{*}$ & $<0.0001$ \\
\hline Multivariable adjusted $\dagger$ & 0.17 (0.16 to 0.18$)$ & $0.42(0.40$ to 0.44$)$ & $1.0^{*}$ & $<0.0001$ \\
\hline
\end{tabular}

* Reference category.

†Adjusted for age, smoking, diabetes, history of hypercholesterolaemia, body mass index, exercise, alcohol consumption, highest educational level, and randomised treatment assignments (aspirin, vitamin $\mathrm{E}$, and $\beta$ carotene); owing to missing covariates, the multivariable (crude) analysis was based on 8346 (8686) events of incident hypertension among 27790 (28 863) women. 
hypertension may more accurately reflect the risk distribution among people with blood pressure levels below 140/90 mm Hg. ${ }^{6}$

Other findings further underscore substantial differences between these two groups. Among participants of the Framingham Study aged below 65, the risk of developing hypertension over a period of four years was $18 \%$ in those with normal blood pressure and $37 \%$ in those with high normal blood pressure. ${ }^{3}$ Our study confirms and expands these findings. Among women with high normal blood pressure at baseline, $64 \%$ progressed to hypertension over a 10 year period, whereas only $34 \%$ of women with initially normal blood pressure developed hypertension during follow-up. The differences in risk were maintained during the entire 10 year follow-up period.

Our study indicates that women who progress to hypertension need to be identified early, as their risk of an adverse outcome is increased shortly thereafter. Women who developed hypertension during the first 48 months of follow-up had a $56 \%$ increased risk of a major cardiovascular event in the last six years of follow-up compared with women who did not develop hypertension during at least four years. Women with high normal blood pressure at baseline and progression to hypertension had a similar cardiovascular risk to women with baseline hypertension.

Taken together, the results of this and other studies suggest that preventive and research efforts to reverse blood pressure progression and reduce cardiovascular events should be focused on people with high normal blood pressure. Several interventions have been shown to be beneficial in this population. Physical exercise effectively reduces blood pressure levels independent of baseline blood pressure. ${ }^{18}$ Dietary intervention was effective in reducing systolic blood pressure by $3.5 \mathrm{~mm} \mathrm{Hg}$ and diastolic blood pressure by $2.1 \mathrm{~mm} \mathrm{Hg},{ }^{19}$ and blood pressure levels were further lowered by restricting dietary sodium intake. ${ }^{20}$ Sodium reduction has recently been shown to potentially reduce cardiovascular events in people with prehypertension. ${ }^{21}$ Consuming a Mediterranean-style diet rich in olive oil and nuts is more effective in reducing blood pressure than a standard low fat diet. ${ }^{22}$

Because women with high normal blood pressure also have an increased prevalence of diabetes and hypercholesterolaemia, a multidimensional intervention programme targeting all cardiovascular risk factors and including dietary modification and regular physical exercise should be the most efficient approach to reduce cardiovascular risk. Several studies have documented the feasibility and efficacy of a multidimensional approach in this group. ${ }^{23-26}$ Interestingly, the PREMIER trial suggested that a minimal counselling programme leads to a substantial reduction in blood pressure $(-7.4 \mathrm{~mm} \mathrm{Hg}$ for systolic blood pressure and $-5.2 \mathrm{~mm} \mathrm{Hg}$ for diastolic pressure) that is sustained over at least 18 months of follow-up. ${ }^{24}$

Whether drug treatment should be used in people with high normal blood pressure is highly controversial. ${ }^{27}$ No trial to date has examined the potential benefit of drug treatment to improve cardiovascular outcome in this large group of people. Thus, without hard endpoint data, blood pressure lowering drugs cannot be recommended, and aggressive lifestyle modifications remain the cornerstone of risk

Table 5 Cox proportional hazards models to assess risk of first major cardiovascular event among women with incident diagnosis of hypertension during first 48 months of follow-up $(n=38787)$

\begin{tabular}{|c|c|c|c|c|c|}
\hline & \multicolumn{4}{|c|}{ Hazard ratio ( $95 \%$ confidence interval) } & \multirow[t]{2}{*}{$\mathrm{P}$ trend } \\
\hline & $\begin{array}{c}\text { No progression* } \\
(n=22886)\end{array}$ & $\begin{array}{r}\text { Progression to } h \\
(n=56)\end{array}$ & $\begin{array}{l}\text { pertension* } \\
\text { 4) }\end{array}$ & $\begin{array}{l}\text { Baseline hypertension* } \\
\qquad(\mathrm{n}=10207)\end{array}$ & \\
\hline \multicolumn{6}{|l|}{ First model } \\
\hline Events/person years & $214 / 137767$ & $106 / 34$ & 38 & $332 / 60250$ & \\
\hline Crude & $0.50(0.40$ to 0.63$)$ & $1.0 \dagger$ & & 1.77 (1.42 to 2.20$)$ & $<0.0001$ \\
\hline Age adjusted $\ddagger$ & $0.60(0.48$ to 0.76$)$ & $1.0 \dagger$ & & 1.51 (1.22 to 1.89$)$ & $<0.0001$ \\
\hline $\begin{array}{l}\text { Multivariable } \\
\text { adjusted§}\end{array}$ & $0.64(0.50$ to 0.81$)$ & $1.0 \dagger$ & & $1.39(1.11$ to 1.74$)$ & $<0.0001$ \\
\hline Second model & & (From below high normal)ף & (From high norm & & \\
\hline Events/person years & $214 / 137767$ & $47 / 19622$ & $59 / 14416$ & $332 / 60250$ & \\
\hline Crude & $0.38(0.29$ to 0.51$)$ & $0.59(0.40$ to 0.86$)$ & $1.0 \dagger$ & 1.35 (1.02 to 1.78$)$ & $<0.0001$ \\
\hline Age adjusted $\ddagger$ & $0.50(0.37$ to 0.66$)$ & 0.68 (0.46 to 1.00$)$ & $1.0 \dagger$ & $1.25(0.95$ to 1.65$)$ & $<0.0001$ \\
\hline $\begin{array}{l}\text { Multivariable } \\
\text { adjusted§ }\end{array}$ & $0.53(0.40$ to 0.72$)$ & $0.70(0.47$ to 1.03$)$ & $1.0 \dagger$ & $1.17(0.88$ to 1.55$)$ & $<0.0001$ \\
\hline \multicolumn{6}{|c|}{$\begin{array}{l}\text { *No progression defined as a blood pressure }<140 / 90 \mathrm{~mm} \mathrm{Hg} \text { at baseline and during at least } 48 \text { months of follow-up in absence of blood pressure } \\
\text { lowering treatment; progression to hypertension defined as blood pressure }<140 / 90 \mathrm{~mm} \mathrm{Hg} \text { without blood pressure lowering treatment at baseline } \\
\text { and developing hypertension during first } 48 \mathrm{months} \text { of follow-up; hypertension defined as previous diagnosis of hypertension, systolic blood pressure } \\
\geq 140 \mathrm{~mm} \mathrm{Hg} \text {, diastolic blood pressure } \geq 90 \mathrm{~mm} \mathrm{Hg} \text {, or receiving blood pressure lowering treatment at baseline. } \\
\text { †Reference category. } \\
\text { †Age at } 48 \text { months of follow-up used for adjustment. } \\
\text { §Adjusted for age, smoking, diabetes, body mass index, and alcohol consumption at } 48 \text { months and for baseline history of hypercholesterolaemia, } \\
\text { exercise, highest educational level, and randomised treatment assignments (aspirin, vitamin E, and } \beta \text { carotene); owing to missing covariates, the } \\
\text { multivariable analysis was based on } 625 \text { (compared with } 652 \text { in the crude and age adjusted analyses) major cardiovascular events during follow-up } \\
\text { among } 37653 \text { women. } \\
\text { IGroup of women with progression to hypertension divided into } 3274 \text { women who had a baseline blood pressure }<130 / 85 \mathrm{~mm} \mathrm{Hg} \text { (below high } \\
\text { normal) and } 2420 \text { who had baseline blood pressure } 130-9 / 85-9 \mathrm{~mm} \mathrm{Hg} \text { (high normal). }\end{array}$} \\
\hline
\end{tabular}




\section{WHAT IS ALREADY KNOWN ON THIS TOPIC}

Observational studies have shown a direct association between cardiovascular risk and blood pressure across a broad spectrum of blood pressure levels

Guidelines use different classification schemes for blood pressure levels currently considered as normal (prehypertension versus normal and high normal blood pressure)

Cardiovascular outcomes among people who progress to hypertension are not well defined

\section{WHAT THIS STUDY ADDS}

Compared with women with normal blood pressure, those with high normal blood pressure have a substantially higher risk of cardiovascular events and incident hypertension

Maintaining two different blood pressure categories for people with prehypertension seems to be appropriate

Risk of cardiovascular events among women who progress to hypertension is increased shortly after a diagnosis of hypertension has been made lifestyle modifications. Although the overall risk of an adverse outcome in women with "prehypertension" is increased, this group is a heterogeneous population. The increase in risk is substantially more pronounced in women with high normal blood pressure. Therefore, a classification using two different categories for people with "prehypertension" may be more accurate. This differentiation is important in order to optimise the implementation of preventive strategies in those women at high risk for adverse events. Once hypertension has developed, the cardiovascular event rate is increased shortly after the diagnosis of hypertension has been made, especially among women with high normal blood pressure at baseline.

We thank the participants of the women's health study for their outstanding commitment and cooperation and the entire women's health study staff for their expert and unfailing assistance.

Contributors: DC and RJG were responsible for the study concept and design. All authors were involved in data acquisition. DC drafted the manuscript. All authors critically revised the manuscript for important intellectual content. DC and RJG did the statistical analysis. DC, PMR, and JEB obtained funding. RJG provided administrative, technical, and material support and supervised the study. DC is the guarantor.

Funding: DC is supported by grants from the Swiss National Science Foundation (PBBSB-113207) and the Janggen-Poehn Foundation, St Gallen, Switzerland. The women's health study was supported by grants HL-43851 and CA-47988 from the National Heart, Lung, and Blood Institute and the National Cancer Institute. The funding agencies had no role in the design, conduct, data management, analysis, or manuscript preparation.

Competing interests: None declared.

Ethical approval: Institutional review board of Brigham and Women's Hospital, Boston.

Provenance and peer review: Non-commissioned; externally peer reviewed. Another possible limitation is the use of self reported blood pressure and hypertension status. However, the prognostic value of self reported blood pressure in cohort studies involving US health professionals is similar to that of directly measured blood pressure in participants of other cohort studies. ${ }^{1}$ Furthermore, the validity of this approach has been examined in the comparable nurses' health study, in which $99 \%$ of the women who reported high blood pressure had their diagnosis confirmed by review of medical records. ${ }^{12}$ Self reported blood pressure, total cholesterol, and body mass index have previously been shown in the women's health study to be strong predictors of cardiovascular risk, with relative risks consistent in magnitude with those seen in other major studies. ${ }^{30-32}$ Systolic blood pressure is the strongest cardiovascular risk factor after age in the women's health study, ${ }^{33}$ further underscoring its predictive validity. Finally, we found correlation coefficients for systolic and diastolic blood pressure categories that were at least as strong as those reported in the literature for office measured blood pressure, indicating consistent reporting of blood pressure over time. ${ }^{13-15}$

\section{Conclusions}

Women with high normal blood pressure have a substantially increased risk of developing hypertension or a major cardiovascular event during follow-up compared with women with normal blood pressure. These people need close follow-up and
1 Lewington S, Clarke R, Qizilbash N, Peto R, Collins R. Age-specific relevance of usual blood pressure to vascular mortality: a metaanalysis of individual data for one million adults in 61 prospective studies. Lancet 2002;360:1903-13.

2 Vasan RS, Larson MG, Leip EP, Evans JC, O'Donnell CJ, Kannel WB, et al. Impact of high-normal blood pressure on the risk of cardiovascular disease. N Engl/ Med 2001;345:1291-7.

3 Vasan RS, Larson MG, Leip EP, Kannel WB, Levy D. Assessment of frequency of progression to hypertension in non-hypertensive participants in the Framingham heart study: a cohort study. Lancet 2001;358:1682-6.

4 Vasan RS, Beiser A, Seshadri S, Larson MG, Kannel WB, D 'Agostino RB, et al. Residual lifetime risk for developing hypertension in middle-aged women and men: the Framingham heart study. JAMA 2002;287:1003-10.

5 Kearney PM, Whelton M, Reynolds K, Muntner P, Whelton PK, He J. Global burden of hypertension: analysis of worldwide data. Lancet 2005;365:217-23.

6 Mancia G, De Backer G, Dominiczak A, Cifkova R, Fagard R, Germano G, et al. 2007 guidelines for the management of arterial hypertension: the Task Force for the Management of Arterial Hypertension of the European Society of Hypertension (ESH) and of the European Society of Cardiology (ESC). J Hypertens 2007;25:1105-87. et al. The seventh report of the Joint National Committee on Prevention, Detection, Evaluation, and Treatment of High Blood Pressure: the INC 7 report. JAMA 2003;289:2560-71.

8 Lee IM, Cook NR, Gaziano JM, Gordon D, Ridker PM, Manson JE, et al. Vitamin $E$ in the primary prevention of cardiovascular disease and cancer: the women's health study: a randomized controlled trial. JAMA 2005;294:56-65.

9 Rexrode KM, Lee IM, Cook NR, Hennekens CH, Buring JE. Baseline characteristics of participants in the women's health study. J Womens Health Gend Based Med 2000;9:19-27.

10 Ridker PM, Cook NR, Lee IM, Gordon D, Gaziano JM, Manson JE, et al. A randomized trial of low-dose aspirin in the primary prevention of cardiovascular disease in women. $N$ Engl J Med 2005;352:1293-304.
7 Chobanian AV, Bakris GL, Black HR, Cushman WC, Green LA, Izzo JL Jr, 
11 Lee IM, Cook NR, Manson JE, Buring JE, Hennekens CH. Beta-carotene supplementation and incidence of cancer and cardiovascular disease: the women's health study. J Natl Cancer Inst 1999;91:2102-6.

12 Colditz GA, Martin P, Stampfer MJ, Willett WC, Sampson L, Rosner B, et al. Validation of questionnaire information on risk factors and disease outcomes in a prospective cohort study of women. Am J Epidemiol 1986;123:894-900.

13 Danesh J, Wheeler JG, Hirschfield GM, Eda S, Eiriksdottir G, Rumley A, et al. C-reactive protein and other circulating markers of inflammation in the prediction of coronary heart disease. N Engl J Med 2004;350:1387-97.

14 Mansoor GA, McCabe EJ, White WB. Long-term reproducibility of ambulatory blood pressure. J Hypertens 1994;12:703-8.

15 Rosner B, Hennekens CH, Kass EH, Miall WE. Age-specific correlation analysis of longitudinal blood pressure data.

Am J Epidemiol 1977; 106:306-13.

16 Cox DR. Regression models and life tables. J Roy Stat Soc $B$ 1972;34:187-220.

17 Kshirsagar AV, Carpenter M, Bang H, Wyatt SB, Colindres RE. Blood pressure usually considered normal is associated with an elevated risk of cardiovascular disease. Am J Med 2006;119:133-41.

18 Whelton SP, Chin A, Xin X, He J. Effect of aerobic exercise on blood pressure: a meta-analysis of randomized, controlled trials. Ann Intern Med 2002;136:493-503.

19 Appel LJ, Moore TJ, Obarzanek E, Vollmer WM, Svetkey LP, Sacks FM, et al. A clinical trial of the effects of dietary patterns on blood pressure. N Engl J Med 1997;336:1117-24.

20 Sacks FM, Svetkey LP, Vollmer WM, Appel LJ, Bray GA, Harsha D, et al. Effects on blood pressure of reduced dietary sodium and the dietary approaches to stop hypertension (DASH) diet. N Engl J Med 2001;344:3-10

21 Cook NR, Cutler JA, Obarzanek E, Buring JE, Rexrode KM, Kumanyika SK, et al. Long term effects of dietary sodium reduction on cardiovascular disease outcomes: observational follow-up of the trials of hypertension prevention (TOHP). BMJ 2007;334:885.

22 Estruch R, Martinez-Gonzalez MA, Corella D, Salas-Salvado J, Ruiz-Gutierrez V, Covas MI, et al. Effects of a Mediterranean-style die on cardiovascular risk factors: a randomized trial. Ann Intern Med 2006;145:1-11.
23 Appel LJ, Champagne CM, Harsha DW, Cooper LS, Obarzanek E, Elmer PJ, et al. Effects of comprehensive lifestyle modification on blood pressure control: main results of the PREMIER clinical trial. JAMA 2003;289:2083-93.

24 Elmer PJ, Obarzanek E, Vollmer WM, Simons-Morton D, Stevens VJ, Young DR, et al. Effects of comprehensive lifestyle modification on diet, weight, physical fitness, and blood pressure control: 18-month results of a randomized trial. Ann Intern Med 2006;144:485-95.

25 Tuomilehto J, Lindstrom J, Eriksson JG, Valle TT, Hamalainen H, Ilanne-Parikka P, et al. Prevention of type 2 diabetes mellitus by changes in lifestyle among subjects with impaired glucose tolerance. N Engl J Med 2001;344:1343-50.

26 Trials of Hypertension Prevention Collaborative Research Group. Effects of weight loss and sodium reduction intervention on blood pressure and hypertension incidence in overweight people with highnormal blood pressure: the trials of hypertension prevention, phase II. Arch Intern Med 1997;157:657-67.

27 Julius S, Nesbitt SD, Egan BM, Weber MA, Michelson EL, Kaciroti N, et al. Feasibility of treating prehypertension with an angiotensinreceptor blocker. N Engl J Med 2006;354:1685-97.

28 Verberk WJ, Kroon AA, Kessels AG, de Leeuw PW. Home blood pressure measurement: a systematic review. J Am Coll Cardiol 2005;46:743-51.

29 Pickering TG, Shimbo D, Haas D. Ambulatory blood-pressure monitoring. N Engl J Med 2006;354:2368-74.

30 Glynn RJ, L'Italien GJ, Sesso HD, Jackson EA, Buring JE. Development of predictive models for long-term cardiovascular risk associated with systolic and diastolic blood pressure. Hypertension 2002;39:105-10.

31 Kurth T, Gaziano JM, Rexrode KM, Kase CS, Cook NR, Manson JE, et al. Prospective study of body mass index and risk of stroke in apparently healthy women. Circulation 2005;111:1992-8.

32 Huang PY, Buring JE, Ridker PM, Glynn RJ. Awareness, accuracy, and predictive validity of self-reported cholesterol in women. J Gen Intern Med 2007;22:606-13.

33 Cook NR, Buring JE, Ridker PM. The effect of including C-reactive protein in cardiovascular risk prediction models for women. Ann Intern Med 2006;145:21-9.

Accepted: 21 June 2007 